\title{
Shifting Structural Complexity: The Production of Clause Types in Speeches Given by English for Academic Purposes Students
}

\author{
Mary Lou Vercellotti ${ }^{\mathrm{a}}$ and Jessica Packer ${ }^{\mathrm{b}}$ \\ ${ }^{\mathrm{a} B a l l}$ State University \\ Department of English \\ Muncie, IN 47306 USA \\ mlvercellott@bsu.edu \\ ${ }^{\mathrm{b}}$ University of Pittsburgh \\ 4200 Fifth Avenue, Pittsburgh, PA 15260 USA
}

Corresponding Author: Mary Lou Vercellotti mlvercellott@bsu.edu, Department of English, Ball State University, Muncie, IN 47306 USA, 765-285-8389

\section{Acknowledgements}

Special thanks to Dorolyn Smith for suggesting this research and to Dawn E. McCormick and Sarah Isaacson for giving feedback on drafts of this paper. Many thanks to the two JEAP reviewers whose feedback greatly improved our argument and writing. The initial findings were presented at Second Language Research Forum 2013 in Provo, UT. The original data collection was funded by National Science Foundation, Grant Number SBE-0836012 to the Pittsburgh Science of Learning Center http://www.learnlab.org.

Vitae

Mary Lou Vercellotti is an Assistant Professor of linguistics in the Department of English at Ball State University. In addition to investigating the development of language skills as measured by performance, she is also studying the impact of noticing, iterations, and prompt on second language learning.

Jessica Packer graduated with a Bachelor of Arts in Linguistics from the University of Pittsburgh in 2014. She currently works in the translation and localization industry. 
Brief author biography

Vitae

Mary Lou Vercellotti is an Assistant Professor of linguistics in the Department of English at Ball State University. In addition to investigating the development of language skills as measured by performance, she is also studying the impact of noticing, iterations, and prompt on second language learning.

Jessica Packer graduated with a Bachelor of Arts in Linguistics from the University of Pittsburgh in 2014. She currently works in the translation and localization industry. 
Graphical Abstract

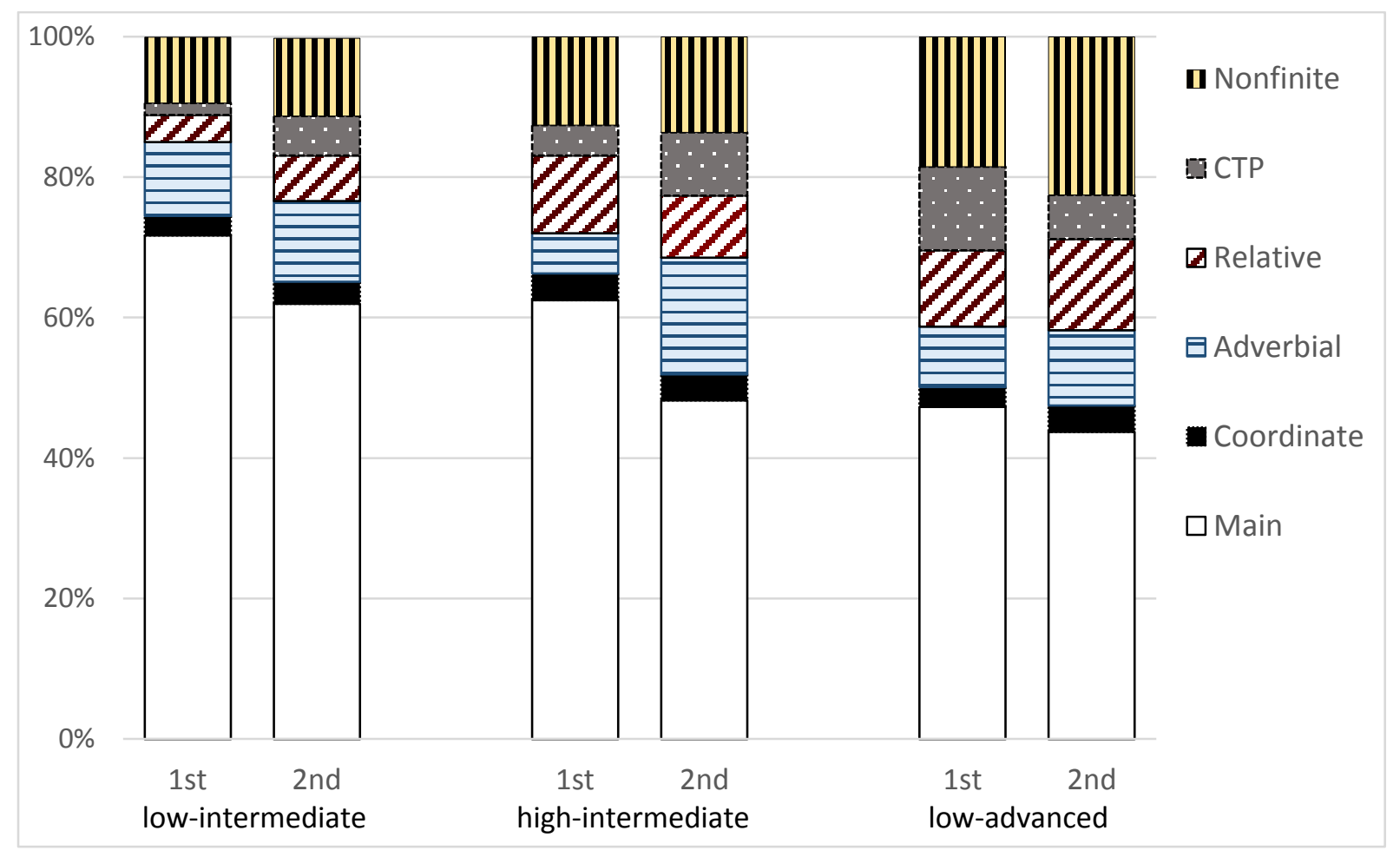

Figure 1 Mean Percentage of Each Clause Type per Assignment within Level 


\section{INTRODUCTION}

With the goal of advancing students' language proficiency, EAP curriculums have included explicit instruction on the structure and function of individual clause types. Finite dependent clauses, in particular, have been extensively covered in grammar classes (Biber \& Gray, 2010). EAP instructors have encouraged students to build complexity into their speech and writing, and they may direct students to identify and/or create specific clause types, such as relative clauses, in isolated tasks. The assessment of student writing and speeches usually has included the requirement to produce a variety of structures. Research (e.g., Mancilla, Polat, \& Akcay, 2015) has found that even advanced nonnative English speakers, however, produce fewer dependent clauses than native speakers in written online discussion posts in a college class. The explicit coverage of the various clause types is crucial in EAP curriculums because of their extensive use in academic settings. For instance, a popular freshman composition book, They say/I say: The Moves that Matter in Academic Writing (Graff, Birkenstein, \& Durst, 2012), describes a template for writing which is focused on the use of multi-clause constructions to organize writing. Further, Deroey (2012) has called for more EAP instruction of a particular subtype of this clause, the wh-cleft (such as, what he says is...), because of its frequent use in academic lectures.

Correspondingly, EAP research has shown increased interest in investigating structural complexity. Banerjee, Franceschina, and Smith (2007) included measures of complexity when reviewing IELTS texts and speeches and found differences in subordination ratios between written and spoken modes. Biber and Gray (2010) reported that dependent clauses are more common in spoken language whereas academic writing tends to complexify at the phrasal level. Informed by Biber and Gray’s findings, Parkinson and Musgrave (2014) investigated the 
development of complexity by focusing on different structures used by advanced EAP students to complexify noun phrases in written texts. Yet, similar work has not been done to fully describe the verbal structures used by EAP learners to complexify speech.

Describing the development of structural complexity (clause relations) in L2 oral data is necessary because language modality is expected to have a clear and distinct impact on language performance, specifically dependent clause types (Biber \& Gray, 2010; Biber, Gray, Staples, 2014). Kormos and Trebits (2012), though, did not find differences in syntactic complexity between EFL texts and speeches, measured by clause length, subordination ratio, and one clause type (relative clauses). A full description of complexity, however, must consider all of the clause types produced (Rimmer, 2006). A description of all clause types produced by students across proficiency levels may suggest a developmental order for the clauses types in ESL speech. Mancilla, Polat, and Akcay (2015) recommended a teaching intervention to address the deficit in production of dependent clauses in nonnative EAP language, but it is unclear which clauses are underused. The current study has applications for the comparison of oral production and (the more commonly researched) written production, for understanding the sequence of development, and for planning EAP instruction and curriculum design. Our goal is to describe the various clause types produced by EAP students during a free-production speaking task across three instruction levels in an intensive English program (IEP) in order to determine which clauses are produced as structural complexity develops.

Because multiple terms are used in the field, the next section explains the clause types as defined in this study with a discussion of the suggested influences on development. We then describe our study's methodology. The results are given and discussed in light of previous 
Production of Clause Types in EAP speeches

findings. The article ends with our conclusions and pedagogical implications, including notes on the study's limitations and future research.

\section{CLAUSE TYPES AND DEVELOPMENT}

Clauses are the "basic structural unit" (Townsend, 1997) of language, and complexity is based on clause relations, with either reciprocal (coordination) or hierarchical (subordination) relationships between elements (Rescher, 1998). Multiple clause types exist, with dependent clauses defined in relation to the main (or independent) clause. In discussions of clause development (e.g., Banerjee, Franceschina, \& Smith, 2007; Diessel, 2004; Ioup, 1983), finite and nonfinite clauses (e.g., gerunds, infinitives) are often classified separately, even though the same clause types (e.g., adverbial, relative, complement) can be used to describe finite and nonfinite constructions. Moreover, finite and nonfinite clauses are generally taught separately in IEPs. Thus, in this paper, nonfinite clauses are discussed separately from finite clauses.

In this study, adverbial clauses are finite clauses connected to a main clause by a subordinate conjunction and give information, often about time, place, reason, purpose, condition, or concession (Collins \& Hollo, 2010). Adverbial clauses are grammatically optional in the sentence (Quirk \& Greenbaum, 1973) and thus are syntactic adjuncts (Collins \& Hollo). Example (1) from the EAP learner data begins with an adverbial clause (bolded).

(1) when I was studying in college I just played with my classmates.

Although adverbial clauses are often considered subordinate clauses (Holmes, 1995), Chafe (1988) stated that main clauses and adverbial clauses have equal status with bidirectional linking. According to Diessel (2013), coordinated clauses and adverbial clauses both develop from the combining of two independent sentences whereas relative, complement, and nonfinite clauses develop from clause expansion and are embedded into the main clause. Creating multi-clause 
utterances by clause combining is expected to be an easier process than clause expansion. For instance, the production of adverbial clauses is easier than embedded relative clauses (Kazemi, 2011).

Relative clauses further specify, identify, or give more information about the referenced noun phrase and, therefore, are often called "adjective clauses" in pedagogical texts. Even though relative clauses are embedded clauses, they are not grammatically required and are also syntactic adjuncts.

(2) there is many thing that I like in it.

Syntactically, relative clauses are gapped clauses (O’Grady, 2011), which means that some element within the relative clause is not overtly expressed but is understood from information in the matrix clause. For instance, in (2), the direct object of the verb like is not expressed within the relative clause as the "gap" is filled by the noun phrase many thing in the main clause. Relative clauses are generally considered more difficult than other structures (Kormos \& Trebits, 2012), such as coordination (Sheldon, 1974) or complement clauses in part because relative clauses have an additional syntactic node in formal syntactic descriptions (Ying, 2004).

(3) I think violence movies should censored by parents.

The multi-clause construction shown in (3) has sometimes been labeled a main clause + "that-complement clause" and has sometimes been labeled as complement-taking predicate (CTP) clause + main clause. CTP clauses license a full sentential complement, which means that a complete finite clause is also needed for grammaticality. CTP clauses most often begin an utterance, as shown in Example (3), but they may be in a medial or the end position. These 
constructions may or may not have the complementizer that (Tagliamonte \& Smith, 2005), and speakers often omit it, especially in less formal language (Biber \& Reppen, 1998).

CTP clauses are the typical structure for introducing reporting speech, so they often include "reporting verbs", such as think, know, said, and may carry evidentiality or epistemic information. ${ }^{1}$ Tagliamonte and Smith (2005) stated that this clause type, led by the prototypical $I$ think, has grammaticalized into an epistemic parenthetical, rather than its "original function of subject plus verb introducing a complement clause" (p. 304). This view is also supported by the lexico-grammatical patterns expressed by these types of EAP verbs. CTP clauses are often common collocations (e.g., this study shows, the evidence suggests) and are more formulaic (e.g., it should be noted that) than constructions in main clauses (Granger \& Paquot, 2009). Further, the presence or absence of the complementizer (e.g., that) is connected to the lexical collocation with the verb in the CTP clause (Tagliamonte \& Smith, 2005; Thompson \& Mulac, 1991) and the subject in the CTP clause (Thompson \& Mulac) rather than information in the other clause of the construction.

Despite the apparent matrix clause status of the CTP clause, it frequently conveys secondary information of the speaker's stance toward the main clause (Kaltenböck, 2013), and often functions as prefabricated formulas in (native speaker) learner speech (Diessel, 2004), much like single words such as obviously or maybe. Further, CTP clauses can serve interactional functions, such as fluency fillers (Kaltenböck). This view flips "the traditional notion of 'dependent clause' upside down, by showing that it is the matrix clause that is actually conceptually dependent..." (Verhagen, 2001, p. 349). Accordingly, many CTP clauses can be

\footnotetext{
${ }^{1}$ Thompson (2002) calls these complement-taking predicates (CTP) with their subjects "CTP phrases" (rather than clauses), seemingly to emphasize their closeness to epistemic/evidential adverbs.
} 
considered syntactic adjuncts (not grammatically necessary) whereas the other, messagecarrying, clause is required.

The focus on CTP clauses (rather than "complement clauses") allows an easy search for such multi-clause constructions, which have been of interest in several studies. In fact, Biber and Reppen (1998) explained that their methodology searched for lexical verbs which "can control a that-clause" (p. 158) and specifically reported the frequency of "VERB + THAT" and "VERB + 0" in Figure 11.3, which means that their coding identified CTP clauses and reported the verbs of the CPT clauses, but this label was not used. Likewise, Parkinson's (2013) article on the "thatcomplement clause" in academic writing studied this construction by looking inside "the clause into which the that-clause is embedded" (p. 429), the CTP clause, for the controlling verb and for the source of the proposition. Therefore, this current study's results are comparable to studies that report the frequency of this multi-clause structure using different labels (e.g., thatcomplement clause, finite verb complement, nominal complement clause).

Since the CTP clause often carries epistemic or pragmatic information, the clause sometimes labeled the dependent finite "complement clause" in these constructions is actually the independent assertion (Diessel, 2013), the main idea (Thompson, 2002). Considering how the propositional content (the message) and epistemic stance interacts in these multi-clause utterances (Gablasova, et al., 2015), and an advantage of the CTP clause label is that it allows the message-carrying clause to be consistently coded as the main clause. Similar, less frequent, constructions that have the same structure (sentential finite clause) with epistemic functions (e.g., it's clear to me that) were also coded as CTP clauses with the proposition labeled as the main clause. In sum, the attention on CTP clauses recognizes this clause type's structure, lexicogrammatical patterns, epistemic function, and relationship to the propositional content. 
Turning to nonfinite clauses (e.g., gerunds, infinitives), these clauses are structurally different from finite clauses because they are "degraded clauses" (Townsend, 1997) as they are not fully inflected and often do not have an expressed subject. Yet, nonfinite clauses have clause status because they refer to full propositions. Unlike the other clause types discussed, they may be either syntactic complements or adjuncts to the matrix verb (Quirk \& Greenbaum, 1973). In example (4) from the data, the nonfinite clause is functioning as a syntactic complement, the direct object to the matrix verb try.

\section{(4) we try to enjoy our life together.}

Ioup's (1983) order of acquisition, based upon the production and the accuracy of elicited written data from Arabic ESL learners, found that nonfinite clauses were more difficult than finite clauses, and she ranked adverbial clauses easier than sentential complement clauses, followed by relative clauses. Biber, Gray, and Poonpon $(2011)^{2}$ offered a different developmental order (with substages) based on written native-speaker (L1) data and recommended that L2 studies test their proposed development of structural complexity. Overall, scholars have rarely investigated the development across clause types, and few empirical studies have focused on free-production oral language. One study with oral data and multiple clause types, Banerjee, Franceschina, and Smith (2007), reported no pattern of dependent clause use by proficiency level. O'Grady's (2011) Difficulty Principle, however, would predict that the frequency of "easy" structures would decrease as the frequency of more difficult clauses increases with higher proficiency.

In summary, despite the importance placed on dependent clauses in EAP instruction and despite the value of a variety of structures as a measure of complexity, little is known about the

\footnotetext{
${ }^{2}$ Since Biber, Gray, and Poonpon's hypothesized developmental sequence includes frequency and function in addition to clause structure in spoken and written registers, it is difficult to generalize into the clause categories used here based on structure alone; interested readers are directed to that paper.
} 
production of each of these clause types in EAP speech. Although these clause types are expected to develop at different times (Lambert \& Kormos, 2014) and some predictions have been made about ESL development, more empirical studies are needed to investigate the development of structural complexity, especially with free-production oral data. Verspoor and Behrens (2011) suggested that a study describing "whether all types of dependent clauses emerge simultaneously or if some occur before others or even if some types of clause go at the expense of others" (p. 37) would elucidate the development of structural complexity. The current study answers this call by tracking the development of clause types in free-production speech across three EAP instruction levels.

\section{METHODOLOGY}

This study's focus on language development research has influenced a number of methodological decisions. First, this research examines learners' production of clause types, not on the mastery of the constructions. Since accurate production of the form was not required, the clauses in these data (as shown by the examples) may not have been fully grammatical. All clauses were assigned to one of the clause types described in Section 3.3, based on its construction, and occasionally a projection of the target form. Second, the coding of the clauses was primarily guided by syntactic structure, theoretically driven by construction grammar and Diessel's (2013) linguistic analysis, rather than function (cf. Biber \& Reppen, 1998). Third, structural complexity was calculated at the sentence-level, following expectations in the field for researching grammar and for development studies (Yang, 2013).

\subsection{Participants}

Participants were ESL learners $(n=66)$, aged $18-35$ years $(M=25.3 ; S D=4.5)$ in an IEP in the United States during 2010. Participants were both male $(n=34)$ and female $(n=32)$, from 
multiple L1 groups: Arabic $(n=43)$, Chinese $(n=16)$, and Korean $(n=7)$. The mixed L1 population represented the learners in this (and other) American IEPs. While all participants had studied English in their home country, this was their first time in an English-speaking country. Upon entrance, the students took multiple proficiency tests to be placed into instruction level: low-intermediate, high-intermediate, and low-advanced. Most students were enrolled in speaking, listening, grammar, reading, and writing classes at the same level. Each class met for fifty minutes per day, four days a week, so full time students were in class approximately seventeen hours per week. The program has attempted to be principally eclectic, including a focus on form and communicative competence strategies.

The IEP's instructional sequence is now briefly described, given the potential impact of instruction on this study's results. This IEP's curriculum introduced and revisited topics, but overall, coordination and adverbial clauses were covered earlier than relative, CTP, and nonfinite clauses. Specifically, while coordination and adverbial clauses were introduced in the lowintermediate level, nonfinite clauses were formally introduced early in the high-intermediate level. Relative clauses were introduced late in the low-intermediate level, revisited late in the high-intermediate level and again in the beginning of the low-advanced, while CTP clauses were not scheduled to be explicitly taught until the low-advanced proficiency level.

\subsection{Data}

As part of the regular speaking curriculum, the participants gave semi-spontaneous twominute monologues on a given topic multiple times per academic semester. (See AUTHORS, DATE for a description of the activity.) The topics varied by semester, by level, and sometimes by class section for pedagogical reasons. See Table 1 for the list of topics and the number of speeches from each. The variety of topics decreases the impact of topic effects on the type of 
clause produced. The number of speech samples per topic was not equal because fluctuations of attendance, driven by a variety of factors: fewer students attend during summer session, more students are placed into the high-intermediate level upon enrollment, and few students remain enrolled for three semesters. Topics were mainly descriptive (e.g., "describe your best friend from childhood..."), but at the low-advanced level, the topics became more evaluative (e.g., "discuss the advantages and disadvantages of living in a computerized society"). The participants completed this speaking task approximately one month $\left(1^{\text {st }}\right)$ and two months $\left(2^{\text {nd }}\right)$ into each semester.

\section{[TABLE 1 HERE]}

\subsection{Data Coding}

The 227 speeches were transcribed and segmented into sentence-level units by a native speaker. The initial segmentation into a base unit is more complicated with oral data than with written data because oral data do not have punctuation to indicate where the speaker intends the "sentence" to end. To handle the complications of segmenting learner speech, a principled coding scheme was consistently applied; the transcripts were coded into AS-units and clauses following Foster, Tonkyn, and Wigglesworth (2000). In this study, an AS-unit is minimally an independent (main) clause with any related dependent clauses. The coding of AS-units has been increasingly adopted by second-language researchers for oral data (Norris \& Ortega, 2009). There are acknowledged ramifications of applying this coding system. First, similar to other research (e.g., Holmes, 1995), the data coding did not include two main clauses connected with a coordinating conjunction (i.e., compound sentence) because this coding system considers such utterances as separate AS-units to counter the potential frequency of run-on sentences in oral data. Therefore, each AS-unit had only one main clause. Admittedly, coding systems which do 
not recognize compound sentences have been criticized (Bardovi-Harlig, 1992); nevertheless we followed the coding scheme as suggested by Foster, Tonkyn, and Wigglesworth. Second, since oral language tends to have many connectors (e.g., so, 'cause) possibly serving as fluency fillers, any complete finite clause beginning with a pause of 500 milliseconds or more was coded as a separate main clause even if it began with a subordinate conjunction. For instance, Examples (5) and (6) show consecutive AS-units from the data. ${ }^{3}$

(5) I'd like to have (0.273) another kind of job as a t-- (0.281) teacher (0.687).

(6) because (0.67) for seven years (0.831) I worked (0.625) as a (0.788) web planner and web designer at financial big company (1.278).

Foster, Tonkyn, and Wigglesworth's structural and temporal coding scheme for oral data renders (6) a separate AS-unit (despite the initial subordinate conjunction ${ }^{4}$ ) because of the long pause (687 milliseconds) at the end of (5). Admittedly, the recommended cut-off point is arbitrary, and pausing patterns differ between speakers. In a study with 66 participants, however, it was impractical to consider individual learner's mean pause length when segmenting the data into AS-units, and so the Foster, Tonkyn, and Wigglesworth's suggested 500 millisecond guideline was followed.

\section{[TABLE 2 HERE]}

All 5,150 clauses were then coded as a main, coordinate, adverbial, relative, CTP, or nonfinite clause. Some of these clause categories include subtypes, but an investigation of the subtypes (by structure or function) was not feasible in this initial study. The coded clause types as described in Section 2 are summarized in Table 2 with examples from the data. The operationalization of clause types in this study generally corresponds to the operationalization of

\footnotetext{
${ }^{3}$ Transcription notes include the following: pauses over 200 milliseconds are indicated by their length in parenthesis (e.g., 0.273), partial words are indicated by - (e.g., t--), and the end of a coded AS-unit is indicated with a period (.). ${ }^{4}$ The 670 millisecond pause after because may also indicate an abandonment of the linking between ideas.
} 
clause types in Banerjee, Franceschina, and Smith (2007) and Ioup (1983). ${ }^{5}$ Since this coding system requires all clauses to have a verb, only coordinated verb phrases (with a shared subject) counted as coordinate clauses. Nonfinite clauses, typically gerunds and infinitives, with an object or adjunct element were coded as nonfinite clauses, following Foster, Tonkyn, and Wigglesworth (2000). Therefore, nonfinite clauses without another element (e.g., I liked playing) was not coded as separate clause.

We were interested in studying language freely produced by the participants, so we checked the data for utterances which were seemingly read from the prompt. For instance, the written prompt shown during the task began with "the topic is..." and the teachers often directed the students to begin with that introductory clause. This instruction, when followed, added a CTP clause to the language sample, but these introductory clauses would not represent free production. For instance, (7) shows an utterance that is interrupted to include the introductory clause (underlined).

(7) describe your favorite meal $f$-- the topic is describe your favorite meal from your childhood

Whenever a speech sample started with the CTP clause the topic is and the utterance showed such evidence of being read from the prompt, it was excluded. Ninety-four such clauses $(1.82 \%$ of the dataset) were excluded, leaving 5,056 clauses to be studied.

\subsection{Data Analyses}

The number of AS-units, the number of clauses, and the number of each clause type were tallied for each speech. The data were sorted by instruction level and assignment (first or

\footnotetext{
${ }^{5}$ Banerjee, Franceschina, and Smith (2007) described only four clause types (and fragments which were defined as verb-less phrases). If CTP clauses and coordinate clauses were in the data, it is unclear how they were labeled. Ioup (1983) studied only dependent clauses, specifically adverbial clauses, relative clauses, sentential complements (which co-occur with CTP clauses, as defined here), and three subtypes of nonfinite clauses (which are combined here); she did not elicit coordinated verb phrases. Diessel (2004) studied the same dependent clauses, separated into finite and nonfinite, but he combined coordinate clauses and verb phrases with finite adverbial clauses.
} 
second), and speeches from different semesters were aggregated. The subordination ratio was calculated as the total number of clauses (of any of the six clause types) divided by the number of AS-units for each speech. This sentence-level calculation captures the construct of subordination (Yang, 2013). The subordination scores of each speech were averaged for each assignment, representing the average subordination for each speech for that assignment $\left(1^{\text {st }}\right.$ or $2^{\text {nd }}$ ) at each level. Such verbal subordination ratios have often been used as a general measure of complexity (Lambert \& Kormos, 2014; Norris \& Ortega, 2003), but subordination ratios count each clause type equally despite the different syntactic constructions (Lambert \& Kormos). Subsequently, complexity was also investigated with the calculation the mean number of each clause type in the speeches within each assignment at each instruction level. As stated, this calculation is based on the sentence-level utterances and was not normalized because as Yang (2013) has pointed out the "occurrence per total number of words for SC [syntactic complexity] structures cannot represent SC at the sentence level" (p. 190) with varying mean length of ASunit, which is plausible in developmental studies. The standard deviations, which represent the distribution of the scores, were also calculated. Finally, the percentage of each clause type ${ }^{6}$ across IEP instruction levels is illustrated in a stacked bar chart, allowing a visual comparison of the changing percentage of the produced clause types per assignment. The combination of mean subordination, mean number of each clause type, and average of each clause type allows comparisons across levels when the number of clauses differs from speech to speech and the number of speeches per level differs. There was substantial variability among students, including zero production of individual clause types, resulting in high standard deviations. With substantial between- and within- individual variation, inferential statistics were not done in this descriptive

\footnotetext{
${ }^{6}$ Main clauses are included in the bar graphs because if excluded the figure would not allow accurate comparisons since the mean number of main clauses is not constant.
} 
study, and as a result, we cannot claim that any differences between scores are meaningful; they may simply be within the expected range of scores in the learner population.

\section{RESULTS AND DISCUSSION}

The full dataset showed that the EAP learners produced an average of 22 clauses within twelve AS-units per two-minute speech with a resulting subordination score of 1.8 clauses per AS-unit. The average number of clauses per two-minute speech tended to increase with increasing proficiency, from around 18.5 clauses at the $1^{\text {st }}$ assignment at the low-intermediate level to over 24 clauses by the $2^{\text {nd }}$ assignment at the low-advanced level. See Table 3.

\section{[TABLE 3 HERE]}

\subsection{Subordination}

Subordination scores increased at the higher instruction levels, as expected (e.g., Yang, 2013), from an average of 1.4 clauses per AS-unit in the $1^{\text {st }}$ assignment at the low-intermediate level to an average of 2.4 clauses per AS-unit in the $2^{\text {nd }}$ assignment at the low-advanced level. The subordination scores indicate that the increases in subordination were meaningful changes in structural complexity, when comparing the mean score of the $1^{\text {st }}$ assignment at each level and when comparing the mean score of the $2^{\text {nd }}$ assignment at each level, based on the critical magnitude of .20 (Ortega, 2003) found in written data. Admittedly, the use of the critical magnitude for writing is questionable with oral data; nonetheless, a similar analysis has yet to been done for spoken data. The subordination scores did not change drastically at each subsequent assignment. For instance, the average subordination score of the speeches for the $1^{\text {st }}$ assignment at the high-intermediate level was similar to the scores for the $2^{\text {nd }}$ assignment at the low-intermediate level. This finding is not surprising; Yang noted that syntactic complexity scores (e.g., subordination ratios) may not increase significantly in adjacent levels in writing 
development, so we can assume the same for structural complexity in oral language development. Also, the mean scores of the $1^{\text {st }}$ assignment at each level included speeches by students new to the IEP, who may have had lower initial scores. In addition, student performance may backslide between academic semesters. With the exception of the very first and last assignments, the subordination scores of the speeches were similar to the mean subordination found by Author and CoAuthor (DATE) with oral narratives given by high-intermediate learners based on picture prompts. This study confirms that EAP learners produced more clauses per speech with increases in proficiency, but the real interest was which clause types were produced.

\subsection{Clause Types}

Table 4 gives the descriptive statistics for each clause type per assignment $\left(1^{\text {st }}\right.$ or $\left.2^{\text {nd }}\right)$ within each instruction level. As a required element of an AS-unit, the main clause was the most common clause type for all assignments. Considering that these EAP students produced more clauses per speech at higher proficiency levels (as shown in Table 3) and that the mean number of main clauses are approximately equal, ${ }^{7}$ the increase in subordination was driven primarily by increasing the number of dependent clauses rather than adding main clauses (additional ASunits).

[TABLE 4 HERE]

Coordination is considered a basic way of complexifying (Norris \& Ortega, 2009), but these participants rarely complexified their speeches by conjoining verb phrases. Coordinate clauses were produced less than once per speech, on average, at every level. Example (8) offers a coordinate clause from the data.

(8) you can go to the beach and see the sunshine.

\footnotetext{
${ }^{7}$ Given the standard deviations, which represents the spread of scores, the means are all close (within one SD).
} 
Since these students entered the program at the intermediate level, they may have already moved beyond coordination as the basic complexifying strategy. As noted, the coding scheme for oral data limited coordinate clauses to only coordinated verb phrases because compound sentences were coded as separate AS-units and because coordinated noun phrases are verbless (i.e., phrasal not clausal). A general, post-hoc, review of the data, however, showed that coordination of noun phrases was also rare.

During the $1^{\text {st }}$ assignment in the low-intermediate level, the only dependent clause types produced more than once on average were adverbial and nonfinite clauses. Of note, only two (of 26) students did not produce an adverbial clause while seven did not produce a nonfinite clause during this assignment. All other clause types were produced less frequently. Adverbial and nonfinite clauses were again more frequently produced for the $2^{\text {nd }}$ assignment, averaging approximately two per speech. Example (9) from the $1^{\text {st }}$ assignment begins with an adverbial clause, and Example (10) from the $2^{\text {nd }}$ assignment at the low-intermediate level ends with one.

(9) when I was a child I had a lot of friends.

(10) the weather is nonappropriate in my country because we have hot weather.

The early production of adverbial clauses was expected because they are structurally similar to main clauses and are frequent constructions in English. Complexifying with adverbial clauses, yet, it was not done extensively, even considering that the coding scheme likely reduced the number of coded adverbial clauses, as described in 3.3 Data Coding.

Nonfinite clauses are shown in Examples (11) from the $2^{\text {nd }}$ assignment at the lowintermediate level and (12) from the $1^{\text {st }}$ assignment at the high-intermediate level. In both examples the nonfinite clause is an infinitive construction, but (11) shows the nonfinite clause as a syntactic complement and (12) shows it functioning as a syntactic adjunct. 
Production of Clause Types in EAP speeches

\section{I decided to go to my city}

many of Muslims come to Medina to see this mosque

Relative and CTP clauses averaged above one occurrence per speech in the $2^{\text {nd }}$

assignment at the low intermediate level. Relative clauses are considered a difficult structure (Kormos \& Trebits, 2012), and the low means reported for the low-intermediate learners may be unsurprising. For the $1^{\text {st }}$ assignment at the high-intermediate level, the mean score for relative clauses rose slightly to above two. It should be noted that the learners in this study produced slightly more relative clauses in total than CTP clauses. Example (13) from this assignment shows a common relative clause structure.

\section{it's really big city that have many huge shopping mall}

During the $2^{\text {nd }}$ assignment at the high-intermediate level, the students again produced more nonfinite and adverbial clauses than the other clauses, but the average number of CTP clauses rose above two per speech. The increase in CTP clauses was similar to results based on written corpora, where lexical verbs to express epistemic information increase at higher levels of non-native proficiency (Hyland \& Milton, 1997). Examples (14) and (15) show CTP clauses expressing epistemic information, in initial position and medial position, respectively.

(14) I believe that they are really accurate.

(15) here in the USA it's clear to me that people don't like it

This finding of generally low and fluctuating production of CTP clauses is inconsistent with the expectation that such clauses (e.g., I think) are likely learned early and subsequently produced as a "chunk" (Boers \& Lindstromberg, 2012). Some clauses in this category were variations which would be less likely learned early and produced as single linguistic units. The overall low production of CTP clauses is also contrary to previous work (e.g., Biber \& Gray, 2010) which 
reported that finite complement (and adverbial) clauses are frequent in speech. However, there are at least two issues to consider when comparing the current results to previous studies: the speech type and the context. Firstly, these speeches were monologues; conversations have more epistemic I thinks (e.g., Gablasova et al., 2015; Zhang \& Sabet, 2014). Secondly, this research studied EAP learner data while other research with oral data (e.g., Biber \& Gray) used L1 English. Since these clauses can also demonstrate a speaker's pragmatic skills in spoken language (Gablasova, et al.), an increased production of CTP clauses may emerge later.

Overall, nonfinite clauses were the most frequently produced dependent clause and rose to an average of approximately five per speech at the low-advanced level. The means of the other clause types varied. As a reminder, these descriptive statistics can only point to trends; it is unclear whether the variation across time is meaningful given the large standard deviations. For instance, recent research (Gablasova et al., 2015) on learners' use of epistemic markers (e.g., I think) has shown large differences between learners, attributed to individual speaker style. Further, since CTP clauses may be used as fluency fillers (Kaltenböck, 2013), and L2 fluency may differ for typological and cultural reasons (De Jong, Groenhout, Schoonen, \& Hulstijn, 2015), such variation in L2 learners' speech is expected. Still, the mean frequencies of all clause types were generally trending higher at the $2^{\text {nd }}$ assignment at the low-advanced level than the $1^{\text {st }}$ assignment at the low-intermediate level. Looking specifically at the means for the CTP clauses, there does seem to be a decrease at the $2^{\text {nd }}$ low-advanced speech. Although this is only post-hoc speculation, it is plausible that the CTP clauses dip because these more advanced learners rely less on this clause type as fluency fillers and/or as a stance marker. More pedagogy-related posthoc speculations on the findings are discussed in Section 5 Conclusion and Pedagogical Implications. 


\subsection{Mean Percentage of Each Clause Type}

Figure 1 shows the ratio of each clause type aggregated by assignment within each instruction level. At least $60 \%$ of all clauses were main clauses until the $2^{\text {nd }}$ assignment at the high-intermediate level when the ratio fell below $50 \%$ and further fell at the low-advanced level. As expected from the figures given in Table 4, coordinate clauses were the smallest percentage $(2.8 \%-3.8 \%)$ across all assignments.

\section{[FIGURE 1 ABOUT HERE]}

Adverbial clauses were approximately $10 \%$ of all clauses with dips at the $1^{\text {st }}$ assignments at the high-intermediate $(5.7 \%)$ and low-advanced level $(8.6 \%)$, but with a peak $(16.6 \%)$ at the $2^{\text {nd }}$ speech at high-intermediate level. Relative clauses were infrequently produced at the lowintermediate level, but later rose to about $10 \%$ of the total clauses, with a high of $13 \%$ at the $2^{\text {nd }}$ assignment at the low-advanced level. These findings are similar to the ratio of relative clauses in EFL texts and speeches reported by Kormos and Trebits (2012). The percentage of CTP clauses started at $1.7 \%$, varied generally under $10 \%$, with a peak of $13.4 \%$ for the $1^{\text {st }}$ assignment at the low-advanced level.

The percentage of nonfinite clauses steadily increased with increasing proficiency doubling from $9.4 \%$ in the $1^{\text {st }}$ assignment at the low-intermediate level to $22.5 \%$ in the $2^{\text {nd }}$ assignment at the low-advanced level. Nonfinite clauses are the only dependent clause which could be required for grammaticality, serving as grammatical subject or direct object, whereas the other clauses (i.e., coordinate, adverbial, relative, and CTP) are at least grammatically optional, which might influence production rates. The prevalence of nonfinite clause type in English likely impacts production of this clause type in EAP speeches. From the shifting percentage illustrated in Figure 1, nonfinite clauses seem to increase at the expense of main 
clauses, somewhat supporting O'Grady’s (2011) Difficulty Principle, but in this dataset there was no clear competition among dependent clauses, as might be predicted in some theories of language development (e.g., Verspoor \& Behrens, 2011). Considering Biber and Reppen’s (1998) findings that learners produced nonfinite clauses where finite clauses would be more acceptable, it is possible that the higher frequency of this clause type was also increased by misuse or overuse.

\section{[FIGURE 2 ABOUT HERE]}

The development order suggested by these data is adverbial clauses, nonfinite clauses, relative clauses and CTP clauses (Figure 2). We feel there are insufficient data to include coordinate clauses. This development order based on production in speech does not match acquisition orders based on other research methodology. Biber, Gray, and Poonpon (2011) expect CTP clauses (at least the prototypical CTP clause I think) to be produced earlier than found here, but their order was proposed for written texts, which might have more epistemic verbs (e.g., I think that ...) than monologues. Ioup (1983) also suggested that CTP clauses are produced earlier than the current data found, perhaps because she elicited the construction. In a free-production task, conversely, learners may avoid production this clause type. In addition, the order proposed here moves nonfinite clauses earlier than Ioup's acquisition order, which is attributed to that study's accuracy requirement.

The high production of nonfinite clauses is noteworthy; they were used at the earliest proficiency level and were steadily, more frequently produced. Overall, they made up $32.7 \%$ of all dependent clauses in the data, which may not be surprising because nonfinite clauses are common in English. Given that frequency has been found to be a prominent factor in LI acquisition for multi-clause structures (Diessel, 2004), the high production of this dependent 
clause type would be expected. However, as Rimmer (2008) noted, frequency itself does not necessarily reflect complexity, and nonfinite clauses have been considered a difficult structure to master. Indeed, Diessel concluded that frequency and complexity both impact production within clause types.

Despite the fact that much of the previous research (e.g., Ioup, 1983; Sheldon, 1974; Ying, 2004) investigated the comparative difficulty among clause types, we infer that the supposed difficulty of the structure did not drive production (or lack-there-of). In support, we point to the differences found between the specific clause types within coordination and subordination. One combined structure, adverbial clauses, was produced early and much more frequently than the other, coordinate clauses. Within the expansion clause types, nonfinite clauses were produced early and much more frequently than relative and CTP clauses. We propose usefulness for communicative expression impacted production more than clause structure or difficulty of the structure. It seems that adverbial clauses and nonfinite clauses were needed or deemed useful by these speakers early on. Both clause types can be used to express the purpose behind the actions in the main clause. For instance, a speaker could explain a reason or purpose with a nonfinite clause as in (12) or with an adverbial clause (e.g., many Muslims come to Medina because it has this mosque $)^{8}$. If structure was the main factor, CTP clauses would be expected to be produced earlier than the gapped relative clause and the degraded nonfinite clause. In fact, nonfinite clauses were often produced by learners despite the assumed difficulty. Therefore, communicative usefulness may impact production more than structural similarity or difficulty.

\footnotetext{
${ }^{8}$ A learner may produce separate AS-units (many Muslims come to Medina/they see this mosque) without clearly expressing the action/reason connection.
} 


\section{CONCLUSION AND PEDAGOGICAL IMPLICATIONS}

We investigated structural complexity by identifying the clause types produced by EAP learners in free production monologues across three instruction levels. The learners produced more complex language at higher instruction levels in an IEP by increasing the number of dependent clauses per AS-unit, but not all clause types emerged simultaneously. Specifically, adverbial clauses were produced early, but nonfinite clauses were increasingly produced and became the most common dependent clause overall. Since these EAP learners seemed to rely heavily on these structures, more instruction time should be devoted to this commonly produced clause, perhaps earlier in the curriculum. These learners rarely produced coordinate clauses but did begin to produce relative and CTP clauses. This paper offers a broad picture of what clause types are produced by EAP learners in speech, advancing empirical knowledge for theoretical and pedagogical applications.

We might consider task and topic effects, important issues in pedagogy and assessment (Author \& CoAuthor, DATE; Yang, 2013). The topics given to the students during this task simply may have not elicited many relative or CTP clauses. A skeptical reader might point out that a different task (e.g., narrative, picture description) may be more likely to elicit relative clauses. Although Kormos and Trebits (2012) found that relative clauses were the most frequently produced dependent clause in narratives and picture descriptions, they reported similar ratios of relative clauses (about 10\%) as found in this study. In fact, several topics from the current study (Table 1) could have elicited narrative-like performances, including topics about describing people. Topics may give the opportunity to produce relative clauses, but speakers can avoid specific constructions in free production regardless of task. Likewise, CTP clauses can be avoided by simply stating the idea without expressing epistemic information (e.g., 
I think, I believe that, it's clear to me that). In particular, the topics given at the $2^{\text {nd }}$ assignment at the low-advanced level seemed to elicit fewer CTP clauses than the topics for the earlier assignment. A post-hoc review showed that speeches on violence in the media produced more CTP clauses than speeches about internet safety. The topic of violence in the media elicited a range of opinions, from banning, to parental censorship (as shown in Example (3)) to individual freedom. The higher use of CTP may reflect an increased pragmatic use of I think clauses when disagreements are expected. This research cannot definitively explain why relative and CTP clauses are overall infrequently produced, but their late production may be driven by communicative need.

Since these findings indicate that the students do not often freely produce relative and CTP clauses, curriculum designers may justify their later placement in the curriculum. For instance, curriculum placement (and learners' preference) may delay instruction on pragmatic features, such as stance-taking and hedging with CTP clauses, given the complexity of the social uses of language. On the other hand, these results may indicate that EAP students are less comfortable with these structures and that more instructional focus is warranted. Perhaps EAP students do not understand or value the descriptive power of relative and CPT clauses. In a corpus study of written texts, Granger (1997) found that learners underuse (and misuse) reduced relative clauses, which is problematic because the syntactic compression in these clauses is common in academic texts. Therefore, EAP leaners may need more instructional focus to increase production of relative clauses to scaffold the understanding of the compressed version in academic language. Similarly, students may not fully understand the use of CTP clauses. Support comes from Granger and Paquot's (2009) corpus research with EFL texts, where “academic verbs" were underused. The underused verb forms concludes and concluded are forms found in 
CTP clauses (e.g., the author concludes/concluded). Given that CTP clauses are infrequent in oral (the current study) and written learner language (Granger \& Paquot), expanded coverage of the function of these clauses may be warranted in EAP curriculums. As Graff, Birkenstein, and Durst (2012) explained, students “enter the conversation” by reporting what others say, summarizing others, and responding with their own ideas; all of which can be effectively done with CTP clause constructions. Moreover, explicit instruction in epistemic stance, as found in CTP clauses, has been effective in increasing learners' production in written texts (Fordyce, 2014). EAP teachers may also want to incorporate corpus data as a pedagogical tool, by reviewing how native speakers use the construction to organize academic arguments, in speech as well as in writing. Similarly, instructors can help learners explore how native speakers use relative clauses to add description.

The findings are often discussed often in relation to research based on text because few studies have been done to explore the production of clauses in speech. The limitations of this study suggests some further research. It is unclear from performance data alone what might have driven the development order shown. The IEP curriculum is a plausible partial explanation for the development order shown in these data. This study did not compare different curricula, so the impact of the curriculum cannot be answered here; nevertheless, this paper can inform future studies on the effect on curriculum design or instruction approach. These results reflect the performance of one population of EAP learners in one IEP over three academic semesters, and this study should be supplemented with studies with language samples from less proficient and more advanced students to further the understanding of the development of structural complexity in ESL oral data. Similar research is necessary in EFL settings, considering that Ortega (2003) reported that ESL learners tend to produce more syntactically complex texts. The data included a 
variety of structures within clause types, and more research is needed to analyze the production of the various subtypes, even the basic main clause category (e.g., passives). Since accuracy in production was not assessed, future research could consider the development of accurate production of clause types, perhaps in combination with testing of declarative knowledge of the structures, because knowledge precedes production in adult instructed language learning. Moreover, future research might consider how production may be influenced by the frequency and function of the clause types in L1s (cf. Zhang \& Sabet, 2014). Overall, these findings are relevant for EAP teachers and curriculum designers for the timing and coverage of each clause type, and theoretically, the results offer an important view of the multidimensionality and development of linguistic complexity in learners' speech. 


\section{References}

Authors. (DATE).

Author \& CoAuthor. (DATE)

Banerjee, J., Franceschina, F., \& Smith, A. M. (2007). Documenting features of written language production typical at different IELTS band score levels. IELTS Research Reports, 7, 249309.

Bardovi-Harlig, K. (1992). A second look at T-unit analysis: Reconsidering the sentence. TESOL Quarterly, 26(2), 390-395.

Biber, D. \& Gray, B. (2010). Challenging stereotypes about academic writing: Complexity, elaboration, explicitness. Journal of English for Academic Purposes, 9, 2-20. doi: 10.1016/j.jeap.2010.01.001

Biber, D., Gray B., \& Poonpon, K. (2011). Should we use characteristics of conversation to measure grammatical complexity in L2 writing development? TESOL Quarterly, 45(1), $5-35$.

Biber, D., Gray, B., \& Staples, S. (2014). Predicting patterns of grammatical complexity across language exam task types and proficiency levels. Applied Linguistics. doi: 10.1093/applin/amu059.

Biber, D. \& Reppen, R. (1998). Comparing native and learner perspectives on English grammar: A study of complement clauses. In S. Granger \& G. Leech (Eds.), Learner English on computer (pp. 145-158). London: Addison Wesley Longman.

Boers, F. \& Lindstromberg, S. (2012). Experimental and intervention studies on formulaic sequences in a second language. Annual Review of Applied Linguistics, 32, 83-110. 
Production of Clause Types in EAP speeches

Chafe, W. (1988). Linking intonation units in spoken English. In J. Haiman and S. A. Thompson (Eds.), Clause combining in grammar and discourse (pp. 1-27). Philadelphia, PA: John Benjamins Publishing Co.

Collins, P. \& Hollo, C. (2010). English Grammar: An Introduction. New York: Palgrave Macmillian.

De Jong, N. H., Groenhout, R., Schoonen, R. \& Hulstijn, J. H. (2015). Second language fluency: Speaking style or proficiency? Correcting measures of second language fluency for first language behavior. Applied Psycholinguistics, 36, 223-243. doi:

10.1017/S0142716413000210.

Deroey, K. L. B. (2012). What they highlight is...: The discourse functions of basic wh-clefts in lectures. Journal of English for Academic Purposes, 11, 112-124. doi: 10.1016/jjeap.2011.10.002

Diessel, H. (2004). The acquisition of complex sentences. Cambridge: Cambridge University Press.

Diessel, H. (2013). Construction Grammar and first language acquisition. In T. Hoffmann \& G. Trousdale (Eds.), The Oxford handbook of construction grammar (pp. 347-364). New York, NY: Oxford University Press.

Fordyce, K. (2014). The differential effects of explicit and implicit instruction on EFL Learners' use of epistemic stance. Applied Linguistics, 35(1), 6-28.

Foster, P., Tonkyn, A., \& Wigglesworth, G. (2000). Measuring spoken language: a unit for all reasons. Applied Linguistics, 21(3), 354-375. 
Gablasova, D., Brezina, V., McEnery, T., \& Boyd, E. (2015). Epistemic Stance in Spoken L2 English: The effect of task and speaker style. Applied Linguistics. doi: 10.1093/applin/amv055.

Graff, G., Birkenstein, C., \& Durst, R. (2012). They say/I say: The moves that matter in academic writing with readings ( $2^{\text {nd }}$ ed.). New York, NY: W. W. Norton \& Company.

Granger, S. (1997). On identifying the syntactic and discourse features of participle clauses in academic English: Native and non-native writers compared. In J. Aarts, I. de Mönnink \& H. Wekker (Eds.), Studies in English language teaching (pp. 185-198). Amsterdam: Rodupi.

Granger, S. \& Paquot, M. (2009). Lexical verbs in academic discourse: A corpus-driven study of learner use. In M. Charles, D. Pecorari, \& S. Hunston (Eds.), Academic writing: At the interface of corpus and discourse (pp. 193-214). New York, NY: Continuum.

Holmes, V. M. (1995). A crosslinguistic comparison of the production of utterances in discourse. Cognition, 54(2), 169-207.

Hyland, K. \& Milton, J. (1997). Qualification and certainty in L1 and L2 Students' writing. The Journal of Second Language Writing, 6(2), 183-205.

Ioup, G. (1983). Acquiring complex sentences in ESL. In K. Bailey, M. Long, \& S. Peck (Eds.), Second language acquisition studies (pp. 41-55). Rowley, MA: Newbury House.

Kaltenböck, G. (2013). The development of comment clauses. In B. Aarts, J. Close, G. Leech, \& S. Wallis (Eds.), The verb phrase in English: Investigating recent language change with Corpora (pp. 286-317). New York, NY: Cambridge University Press.

Kazemi, A. (2011). An investigation into the relationship between the type of self-repair and structural complexity of utterance. Journal of English and Literature, 2(4), 96-102. 
Production of Clause Types in EAP speeches

Kormos, J. \& Trebits, A. (2012). The role of task complexity, modality, and aptitude in narrative task performance. Language Learning, 62(2), 439-472. doi: 10.111/j.14679922.2012.0695.x

Lambert, C. \& Kormos, J. (2014). Complexity, accuracy, and fluency in task-based L2 research: Toward more developmentally based measures of second language acquisition. Applied Linguistics, 35(5), 607-614.

Mancilla, R. L., Polat, N. \& Akcay, A. O. (2015). An investigation of native and nonnative English speakers' levels of written syntactic complexity in asynchronouns online discussions. Applied Linguistics. doi: 10.1093/applin/amv012

Norris J. M., \& Ortega, L. (2009). Towards an organic approach to investigating CAF in instructed SLA: The case of complexity. Applied Linguistics, 30(4), 555-578. doi: 10.1093/applin/amp044

O’Grady, W. (2011). Relative clauses: Processing and acquisition. In E. Kidd (Ed.), The acquisition of relative clauses: Processing, typology and function (pp. 13-38). Philadelphia, PA: John Benjamins Publishing Co.

Ortega, L. (2003). Syntactic complexity measures and their relationship to L2 proficiency: A Research synthesis of college-level L2 writing. Applied Linguistics, 24(4), 492-518.

Parkinson, J. (2013). Adopting academic values: Student use of that-complement clauses in academic writing. System, 41, 428-442. doi: 10.1016/j.system.2013.03.002

Parkinson, J. \& Musgrave, J. (2014). Development of noun phrase complexity in the writing of English for Academic Purposes students. Journal of English for Academic Purposes, 14, 48-59. doi: 10.1016/j.jeap.2013.12.001 
Quirk, R. \& Greenbaum, S. (1973). A concise grammar of contemporary English. New York: Harcourt Brace Jovanovich.

Rescher, N. 1998. Complexity. A Philosophical Overview. New Brunswick, NJ: Transaction Publishers.

Rimmer, W. (2006). Putting grammatical complexity in context. Literacy, 42(1), 29-35.

Rimmer, W. (2008). Measuring grammatical complexity: The Gordian knot. Language Testing, 23(4), 497-519.

Sheldon, A. (1974). The role of parallel function in the acquisition of relative clauses in English. Journal of Verbal Learning and Verbal Behavior, 13, 272-281.

Tagliamonte, S. \& Smith, J. (2005). No momentary fancy! The Zero complementizer in English dialects. English Language and Linguistics, 9(2), 289-309. doi:

$10.1017 / \mathrm{S} 130674305001644$

Thompson, S. A. (2002). "Object complements" and conversation: Towards a realistic account. Studies in Language, 26(1), 125-164.

Thompson, S. A. \& Mulac, A. (1991). The discourse conditions for the use of the complementizer that in conversational English. Journal of Pragmatics, 15(3), 237-251.

Townsend, D. J. (1997). Processing clauses and their relationships during comprehension. In J. Costermans \& M. Fayol (Eds.), Processing interclausal relations in the production and comprehension of text (pp. 265-282). Hillsdale, NJ: Erlbaum.

Verhagen, A. (2001). Subordination and discourse segmentation revisited, or: Why matrix clauses may be more dependent than complements. In T. Sanders, J. Schilperood, \& W. Spooreen (Eds.), Text Representation. Linguistics and Psychological Aspects (pp. 337357). Philadelphia, PA: John Benjamins Publishing Co. 
Verspoor, M. \& Behrens, H. (2011). Dynamic systems theory and a usage-based approach to second language development. In M. Verspoor, K. de Bot \&. W. Lowie (Eds.), A dynamic approach to second language development (pp. 25-38). Philadelphia, PA: John Benjamins Publishing Co.

Yang, W. (2013). Response to Biber, Gray, and Poonpon (2011). TESOL Quarterly, 47(1), 187191.

Ying, H. G. (2004). Relevance mapping: A study of language learners' processing of syntactically ambiguous sentences in English. Second Language Research, 20(3), 232255.

Zhang, G. Z. \& Sabet, P. G. P. (2014). Elastic 'I think': Stretching over L1 and L2. Applied Linguistics. doi: 10.1093/applin/amu020. 
Table 1 Topics Given to Elicit Speech Samples for Each Assignment in Each Instruction Level

\begin{tabular}{|c|c|c|c|c|c|}
\hline Level & Assignment & & Topics & & Total \\
\hline \multirow{2}{*}{$\begin{array}{l}\text { low- } \\
\text { intermediate }\end{array}$} & $1^{\mathrm{st}}$ & $\begin{array}{l}\text { childhood friend } \\
\text { (16 speeches) }\end{array}$ & $\begin{array}{l}\text { childhood meal } \\
\text { (10 speeches) }\end{array}$ & & 26 \\
\hline & $2^{\text {nd }}$ & $\begin{array}{l}\text { a surprise } \\
\text { (16 speeches) }\end{array}$ & $\begin{array}{l}\text { transportation } \\
\text { (10 speeches) }\end{array}$ & & 26 \\
\hline \multirow{2}{*}{$\begin{array}{l}\text { high- } \\
\text { intermediate }\end{array}$} & $1^{\mathrm{st}}$ & $\begin{array}{l}\text { home city } \\
\text { (42 speeches) }\end{array}$ & $\begin{array}{l}\text { world problem } \\
\text { ( } 24 \text { speeches) }\end{array}$ & & 66 \\
\hline & $2^{\text {nd }}$ & $\begin{array}{l}\text { a custom } \\
\text { ( } 42 \text { speeches) }\end{array}$ & $\begin{array}{l}\text { a regret } \\
\text { ( } 24 \text { speeches) }\end{array}$ & & 66 \\
\hline \multirow{2}{*}{$\begin{array}{c}\text { low- } \\
\text { advanced }\end{array}$} & $1^{\text {st }}$ & $\begin{array}{l}\text { media violence } \\
\text { (16 speeches) }\end{array}$ & $\begin{array}{l}\text { computerized society } \\
\text { (6 speeches) }\end{array}$ & & 22 \\
\hline & $2^{\text {nd }}$ & $\begin{array}{l}\text { internet safety } \\
\text { (8 speeches) }\end{array}$ & $\begin{array}{l}\text { lifestyles } \\
\text { (5 speeches) }\end{array}$ & $\begin{array}{l}\text { rich/poor } \\
\text { (8 speeches) }\end{array}$ & 21 \\
\hline
\end{tabular}

Table 2 Six Clause Types as Defined in This Study with Examples from the Data

\begin{tabular}{|c|c|c|}
\hline Type & Definition & Example \\
\hline Main & $\begin{array}{l}\text { sentential clause with a subject and a finite verb; } \\
\text { required clause }\end{array}$ & $\begin{array}{l}\text { ah around the world they cut } \\
\text { plants }\end{array}$ \\
\hline Coordinate & $\begin{array}{l}\text { finite verb phrase often connected to another clause by a } \\
\text { coordinating conjunction }\end{array}$ & $\begin{array}{l}\text { a lot of people like him } \\
\text { and listen to his singer }\end{array}$ \\
\hline Adverbial & $\begin{array}{l}\text { sentential clause with a subject and a finite verb, } \\
\text { connected to the main clause by a subordinate conjunction }\end{array}$ & $\begin{array}{l}\text { if you go there } \\
\text { you have a lot of fun }\end{array}$ \\
\hline Relative & $\begin{array}{l}\text { embedded "gapped" sentential clause with a finite verb, } \\
\text { may be introduced by a relative proform }\end{array}$ & $\begin{array}{l}\text { The aspect I liked is the } \\
\text { winters }\end{array}$ \\
\hline СТP & $\begin{array}{l}\text { finite clause which has a sentential clause as its complement, } \\
\text { may include a complementizer connector (e.g., that) }\end{array}$ & I think I'm fine \\
\hline Nonfinite & $\begin{array}{l}\text { clause with a verb not marked for tense or agreement, } \\
\text { must have an object or adjunct element }\end{array}$ & I always liked to play with her \\
\hline
\end{tabular}


Table 3 Mean Number of Clauses and Mean Subordination Ratio (with Standard Deviations) by Assignment and Level

\begin{tabular}{|cccc|}
\hline \multirow{2}{*}{ Level } & Assignment & $\begin{array}{c}\text { Mean clauses/speech } \\
\text { (Standard Deviation) }\end{array}$ & $\begin{array}{c}\text { Mean subordination score } \\
\text { (Standard Deviation) }\end{array}$ \\
\hline \multirow{2}{*}{ low-intermediate } & 1st & $\mathbf{1 8 . 5 0}(5.65)$ & $\mathbf{1 . 4 0}(0.27)$ \\
\cline { 2 - 5 } & 2nd & $\mathbf{2 0 . 6 2}(8.53)$ & $\mathbf{1 . 6 1}(0.35)$ \\
\hline \multirow{2}{*}{ high-intermediate } & 1st & $\mathbf{2 1 . 9 1}(6.29)$ & $\mathbf{1 . 6 4}(0.44)$ \\
\cline { 2 - 5 } & 2nd & $\mathbf{2 4 . 1 1}(7.73)$ & $\mathbf{2 . 1 2}(0.47)$ \\
\hline \multirow{2}{*}{ low-advanced } & 1st & $\mathbf{2 6 . 7 7}(9.39)$ & $\mathbf{2 . 1 2}(0.41)$ \\
\cline { 2 - 5 } & 2nd & $\mathbf{2 4 . 1 4}(6.36)$ & $\mathbf{2 . 4 0}(0.66)$ \\
\hline
\end{tabular}

Table 4 Mean Number (Standard Deviation) of Each Clause Type by Assignment and Instruction Level

\begin{tabular}{|c|c|c|c|c|c|c|c|}
\hline Level & ment & Main & Coordinate & Adverbial & Relative & CTP & Nonfinite \\
\hline \multirow{2}{*}{$\begin{array}{l}\text { low- } \\
\text { intermediate }\end{array}$} & $1^{\mathrm{st}}$ & $\begin{array}{l}\mathbf{1 2 . 8 9} \\
(3.34) \\
\end{array}$ & $\begin{array}{c}\mathbf{0 . 5 0} \\
(1.03) \\
\end{array}$ & $\begin{array}{c}\mathbf{1 . 8 9} \\
(1.56) \\
\end{array}$ & $\begin{array}{c}\mathbf{0 . 6 9} \\
(1.05) \\
\end{array}$ & $\begin{array}{c}\mathbf{0 . 3 1} \\
(0.74) \\
\end{array}$ & $\begin{array}{c}\mathbf{1 . 6 9} \\
(1.67) \\
\end{array}$ \\
\hline & $2^{\text {nd }}$ & $\begin{array}{l}\mathbf{1 2 . 5 0} \\
(4.32)\end{array}$ & $\begin{array}{c}\mathbf{0 . 6 2} \\
(1.06)\end{array}$ & $\begin{array}{c}\mathbf{2 . 3 1} \\
(2.45)\end{array}$ & $\begin{array}{c}\mathbf{1 . 3 1} \\
(1.23)\end{array}$ & $\begin{array}{c}1.12 \\
(1.56)\end{array}$ & $\begin{array}{c}2.23 \\
(2.05)\end{array}$ \\
\hline \multirow{2}{*}{$\begin{array}{l}\text { high- } \\
\text { intermediate }\end{array}$} & $1^{\mathrm{st}}$ & $\begin{array}{l}\mathbf{1 3 . 4 7} \\
(3.70) \\
\end{array}$ & $\begin{array}{c}\mathbf{0 . 8 2} \\
(1.09) \\
\end{array}$ & $\begin{array}{c}\mathbf{1 . 2 3} \\
(1.27) \\
\end{array}$ & $\begin{array}{c}\mathbf{2 . 3 6} \\
(1.77) \\
\end{array}$ & $\begin{array}{c}\mathbf{0 . 9 2} \\
(1.36) \\
\end{array}$ & $\begin{array}{c}\mathbf{2 . 7 3} \\
(2.73) \\
\end{array}$ \\
\hline & $2^{\text {nd }}$ & $\begin{array}{l}\mathbf{1 1 . 4 8} \\
(3.87)\end{array}$ & $\begin{array}{c}\mathbf{0 . 8 8} \\
(1.10)\end{array}$ & $\begin{array}{c}\mathbf{3 . 9 7} \\
(2.31)\end{array}$ & $\begin{array}{c}\mathbf{2 . 1 1} \\
(1.87)\end{array}$ & $\begin{array}{l}\mathbf{2 . 1 5} \\
(2.03)\end{array}$ & $\begin{array}{c}\mathbf{3 . 2 4} \\
(2.39)\end{array}$ \\
\hline \multirow{2}{*}{$\begin{array}{l}\text { low- } \\
\text { advanced }\end{array}$} & $1^{\mathrm{st}}$ & $\begin{array}{l}\mathbf{1 2 . 4 5} \\
(4.03)\end{array}$ & $\begin{array}{c}\mathbf{0 . 7 3} \\
(1.08)\end{array}$ & $\begin{array}{c}2.27 \\
(1.58)\end{array}$ & $\begin{array}{c}\mathbf{2 . 8 6} \\
(2.25)\end{array}$ & $\begin{array}{c}\mathbf{3 . 1 4} \\
(2.17)\end{array}$ & $\begin{array}{c}\mathbf{4 . 8 6} \\
(3.30)\end{array}$ \\
\hline & $2^{\text {nd }}$ & $\begin{array}{l}\mathbf{1 0 . 2 9} \\
(3.32)\end{array}$ & $\begin{array}{c}\mathbf{0 . 9 1} \\
(1.04)\end{array}$ & $\begin{array}{c}\mathbf{2 . 5 2} \\
(2.02)\end{array}$ & $\begin{array}{c}\mathbf{3 . 0 5} \\
(2.01)\end{array}$ & $\begin{array}{c}\mathbf{1 . 4 8} \\
(2.06)\end{array}$ & $\begin{array}{c}\mathbf{5 . 2 9} \\
(3.10)\end{array}$ \\
\hline
\end{tabular}

Note: Without inferential statistics, it is unclear whether variation is meaningful; these descriptive statistics can only point to trends. 


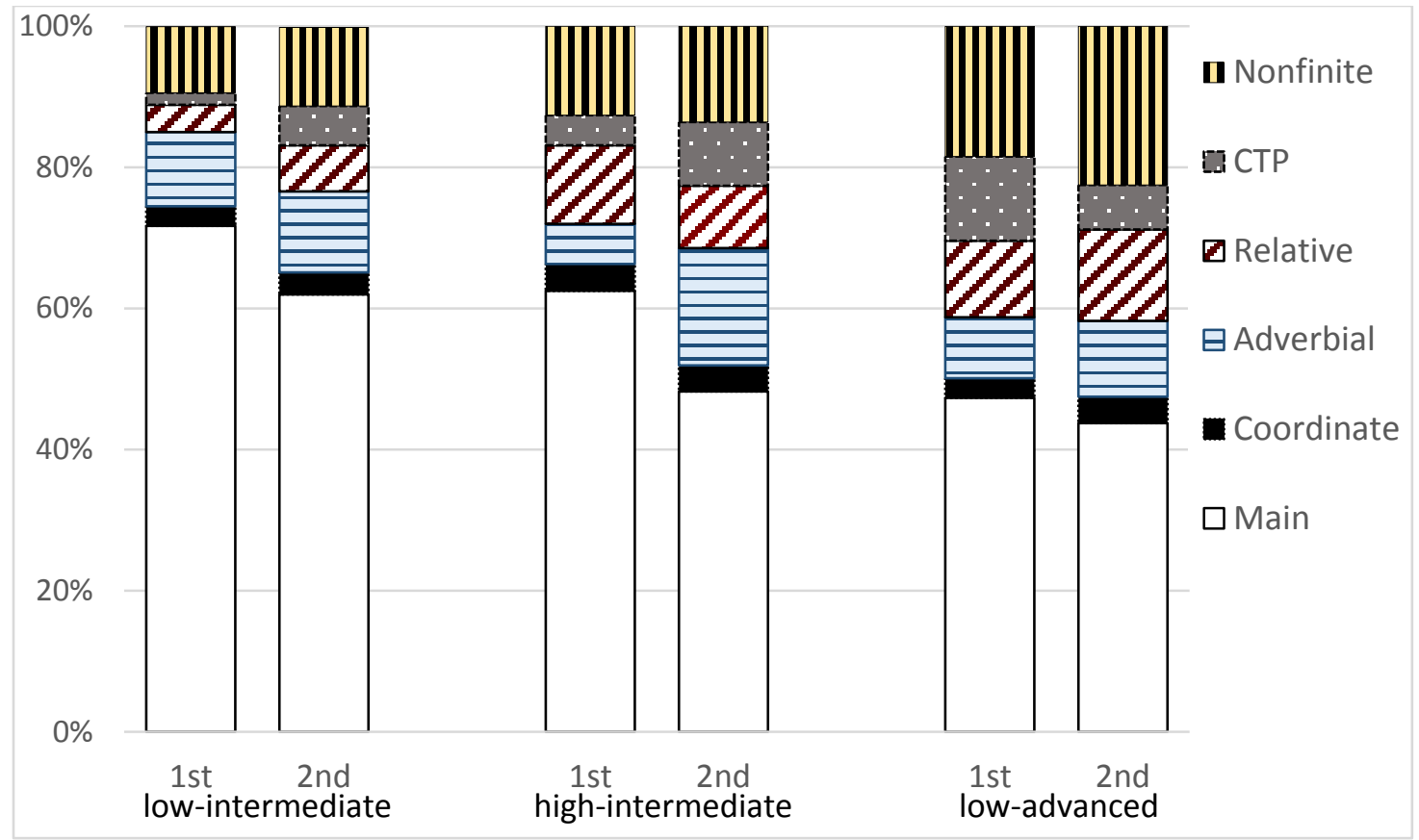

Figure 1 Mean Percentage of Each Clause Types per Assignment within Level

Adverbial $>$ Nonfinite $>$ Relative - CTP

Figure 2 Proposed Development Order Based on Free-Production Speech Data 